\title{
DEBATE
}

\section{Persistent toxic chemicals in the US food supply*}

\author{
Guest Editor: M Porta; Assistant Editor: E Zumeta
}

\section{K S Schafer, S E Kegley}

J Epidemiol Community Health 2002;56:813-817

Persistent organic pollutants (POPs) have spread throughout the global environment to threaten human health and damage ecosystems, with evidence of POPs contamination in wildlife, human blood, and breast milk documented worldwide. Based on data from the US Food and Drug Administration, this article provides a brief overview of POPs residues in common foods in the United States food supply. The analysis focuses on 12 chemical compounds now targeted for an international phase out under the Stockholm Convention on POPs. The available information indicates that POPs residues are present in virtually all categories of foods, including baked goods, fruit, vegetables, meat, poultry, and dairy products. Residues of five or more persistent toxic chemicals in a single food item are not unusual, with the most commonly found POPs being the pesticides DDT (and its metabolites, such as DDE) and dieldrin. Estimated daily doses of dieldrin alone exceed US Environmental Protection Agency and US Agency for Toxic Substances Disease Control reference dose for children. Given the widespread occurrence of POPs in the food supply and the serious health risks associated with even extremely small levels of exposure, prevention of further food contamination must be a national health policy priority in every country. Implementation of the Stockholm Convention will prevent further accumulation of persistent toxic chemicals in food. Early ratification and rapid implementation of this treaty should be an urgent priority for all governments.

W hat image does the phrase "chemically contaminated food" bring to mind? Perhaps alar contaminated apples, with boxes of the fruit in disposal bins outside of grocery stores? An industrial accident near a farming area where clouds of dust and toxic chemicals leave a thick white residue on the broccoli plants? A groaning table filled with holiday dishes-roast turkey, winter squash, mashed potatoes, green beans, rolls and butter? This last image probably doesn't evoke the same response as the first two, yet it is just as likely to represent a hazard, largely because of the widespread contamination of the food supply with persistent organic pollutants (POPs), a class of chemicals that are among the most insidiously dangerous compounds ever produced.

This class of chemical agents includes many organochlorine pesticides such as chlordane, dieldrin, DDT (and its main metabolite, DDE), aldrin, endrin, heptachlor, hexachlorobenzene, mirex, and toxaphene. POP chemicals targeted for inter-

*This paper is based on the report Nowhere to hide: persistent toxic chemicals in the US food supply. San Francisco: Pesticide Action Network, 2001, in which the full dataset used for the analysis can be found. Fully available at http://www.panna.org/resources/documents/ nowhereToHideAvail.dv.html national phase out also include industrial chemicals and byproducts of certain manufacturing processes and waste incineration such as polychlorinated biphenyls (PCBs), dioxins, and furans.

The characteristics that make POPs chemicals unique also make them an urgent global environmental health problem. Because of their physical properties, these chemicals:

- persist in the environment for many years;

- concentrate in fatty tissues and bioaccumulate as they move up the food chain;

- travel long distances in global air and water currents, generally moving from tropical and temperate regions to concentrate in the northern latitudes; and

- have been linked with serious health effects in humans and other living organisms, even at very low exposures.

In just a few decades, POPs have spread throughout the global environment to threaten human health and damage land and water ecosystems. All living organisms on Earth now carry measurable levels of POPs in their tissues. POPs have been found in sea mammals at levels high enough to qualify their bodies as hazardous waste under US law, ${ }^{1}$ and evidence of POPs contamination in human blood and breast milk has been documented worldwide. ${ }^{23}$

There is strong evidence that exposure to even miniscule amounts of POPs at critical periods of developmentparticularly in utero-can cause irreversible damage. The effects of such exposures may take years to develop, sometimes appearing first in the offspring of exposed parents.

Despite their hazards, these chemicals continue to be produced, used, and stored in many countries. Even where national bans or other controls exist, these restrictions are often poorly enforced-and in any case, they cannot protect citizens from exposure to POPs that have migrated from other regions where these chemicals are still in use.

Even though most POPs have already been banned in many countries, their persistence, combined with the fact that production and release into the global environment still occur in some countries, ensures that they make their way into the world's food supply.

Once released to air, water, and soil, these chemicals do not break down readily by natural processes. Some have half lives measured in decades, and they remain in water and soil where they are taken up by plants and animals that ultimately provide food for humans. It is no surprise, therefore, that POPs are pervasive in store bought food as well as in fish and wildlife.

To determine the extent of contamination of the food supply and estimate exposure potential, we analysed US Food and Drug Administration (FDA) data on POPs residues in common foods in the US. ${ }^{4}$ The results are sobering and suggest that we

Abbreviations: POPs, persistent organic pollutants; PCBs, polychlorinated biphenyls 
Table 1 POPs exposures from a typical daily diet in the western US

\begin{tabular}{|c|c|c|c|c|c|c|c|c|c|}
\hline & Chlordane & DDE & DDT & Dieldrin & Dioxin & Endrin & Heptachlor & Hexachlorobenzene & Toxaphene \\
\hline Apple & & $x$ & & & & & & & \\
\hline Blueberry muffin & & $\mathrm{x}$ & & & & & & & \\
\hline Cantaloupe & & $\mathrm{x}$ & & $x$ & & $\mathrm{x}$ & $\mathrm{x}$ & & $\mathrm{x}$ \\
\hline Carrots & & $\mathrm{x}$ & $\mathrm{x}$ & $x$ & & & & & \\
\hline Cheddar cheese & & $\mathrm{x}$ & & $\mathrm{x}$ & $x$ & & $\mathrm{x}$ & $\mathrm{x}$ & \\
\hline Cucumber & $x$ & $\mathrm{x}$ & & $\mathrm{x}$ & & $\mathrm{x}$ & $\mathrm{x}$ & & $x$ \\
\hline French dressing & & & & $\mathrm{x}$ & & & & & \\
\hline Granola & & $\mathrm{x}$ & & & & & & & \\
\hline Green pepper & & $\mathrm{x}$ & & & & & & & \\
\hline Milk, $2 \%$ & & $\mathrm{x}$ & & $\mathrm{x}$ & $\mathrm{x}$ & & & & \\
\hline Skim milk & & $\mathrm{x}$ & & & & & & & \\
\hline Peanuts & & $x$ & & $\mathrm{x}$ & & & & $\mathrm{x}$ & $x$ \\
\hline Potatoes & & $\mathrm{x}$ & & $\mathrm{x}$ & & & & & \\
\hline Radish & $x$ & $\mathrm{x}$ & $\mathrm{x}$ & $x$ & & $x$ & $\mathrm{x}$ & & $\mathrm{x}$ \\
\hline Salmon & & $\mathrm{x}$ & $\mathrm{x}$ & $x$ & & & $\mathrm{x}$ & $\mathrm{x}$ & \\
\hline Sherbet & & $\mathrm{x}$ & & $\mathrm{x}$ & & & & & \\
\hline Spinach & & $\mathrm{x}$ & $\mathrm{x}$ & $\mathrm{x}$ & & & $\mathrm{x}$ & & $x$ \\
\hline Strawberries & & $\mathrm{x}$ & & $\mathrm{x}$ & & & & & $x$ \\
\hline Summer squash & $x$ & $\mathrm{x}$ & $x$ & $x$ & & $x$ & $x$ & $\mathrm{x}$ & $x$ \\
\hline Yogurt & & $\mathrm{x}$ & & & $x$ & & & & \\
\hline
\end{tabular}

Breakfast: yogurt/granola; cantaloupe slice; blueberry muffin; coffee/2\% milk. Lunch: spinach salad w/radish, bell pepper, cucumber, French dressing quesadilla (tortilla w/cheddar cheese); strawberries; skim milk. Dinner: baked salmon; rice; stir fried vegetables (carrot, summer squash, potatoes); fruit sherbet. Snacks: trail mix with peanuts; apple.

are now paying the price for past use of these chemicals-and may continue to pay for some time to come.

\section{METHODS USED TO EVALUATE POPs IN THE US FOOD SUPPLY}

Our study of POPs in the US food supply was designed to paint an accurate picture of dietary exposure to POPs in the US, using available federal government and university data. The chemicals examined in the report are the 12 compounds now targeted for an international phase out under the Stockholm Convention (to which we refer later in the article).

Data on POPs levels in food items were drawn primarily from the latest findings of US FDA's Total Diet Study (TDS). ${ }^{5}$ This study reports the mean, minimum, and maximum values of pesticide residues found in samples taken from a random, off the shelf "market basket" survey of fresh and processed foods consumed in the United States. The FDA POPs residue data were supplemented by more comprehensive annual pesticide residue data on fruits and vegetables from the US Department of Agriculture's Pesticide Data Program. ${ }^{6-8}$ Given the random nature of sampling, some foods (which, none the less, may also be contaminated with POPs) do not appear in these databases.

Analysis of potential dioxin residues on selected food items is included in our study. As neither the FDA nor the US Department of Agriculture test regularly for the presence of dioxins and furans, data on potential occurrence and concentrations of dioxin residues were drawn from results of prior US EPA and university dioxin residue research. ${ }^{9}{ }^{10}$ Information on PCB contaminated foods such as fish, which represent a recognised health risk, is not included in the FDA analysis or in our analysis of residues for this study (see page 22 of original report for data on PCBs in fish). ${ }^{4}$

Typical daily diets were constructed for four regions in the US, reflecting foods typically eaten in each region. The data were then analysed to determine the number and concentrations of POPs residues found in each food item for each of these daily meal plans. The analysis included the determination of the number of "hits" of POPs exposure an individual would receive in an average day, where a "hit" is defined as the occurrence of one POP chemical in a single food item.

The typical daily diets were used in combination with the average and maximum FDA determined residue levels to estimate average and maximum exposures to a particular POPs chemical—dieldrin—for children and adults (in mg of chemical per kilogram of body weight per day). For each food item in the daily diet, the mean dieldrin residue (in $\mathrm{mg} / \mathrm{kg}$ ) reported in the FDA Total Diet Study was multiplied by an estimated portion size (in $\mathrm{kg}$ ) to obtain the mg of dieldrin ingested with that particular food. The total dose of dieldrin ingested in $\mathrm{mg}$ of dieldrin per $\mathrm{kg}$ of body weight per day was calculated by summing the milligrams of chemical ingested with all food items and dividing by $70 \mathrm{~kg}$ (average adult weight for adult diet) or $20 \mathrm{~kg}$ (average child weight for child diet). Because only $10 \%$ of samples tested contained dieldrin residues, the total estimated amount ingested was multiplied by 10\% to obtain the final estimate of exposure in mg of dieldrin per $\mathrm{kg}$ of body weight per day. (The percentage of samples contaminated varied considerably depending on the identity of the food, the sampling year and the country of origin. For example, in 1998, $78 \%$ of frozen winter squash samples from the US contained dieldrin residues, while only $15 \%$ of fresh US winter squash samples contained residues. That same year, $0.8 \%$ of fresh Mexican winter squash contained dieldrin residues. See Groth et al. ${ }^{8}$ )

To put the levels of POPs in food in perspective, these estimated daily dietary exposures were compared with health based exposure thresholds established by the US EPA and the Agency for Toxic Substances and Disease Registry (ATSDR). ${ }^{11}$

\section{RESULTS AND DISCUSSION}

Analysis of the data shows that POPs residues are present in virtually all categories of foods, including baked goods, fruit, vegetables, meat, poultry, and dairy products. Residues of five or more persistent toxic chemicals in a single food item were not unusual, with the most commonly found POPs being DDT and its metabolites (found in $21 \%$ of samples tested in 1998 and $22 \%$ in 1999), and dieldrin (found in $10 \%$ of samples tested in 1998 and $12 \%$ in 1999). ${ }^{12}{ }^{13}$ Dieldrin and DDT are both highly persistent and toxic organochlorine pesticides. Dieldrin was banned in the US in the late 1970s. Because of widespread environmental damage, DDT was banned in the US in 1972.

Data from FDA's "market basket" diet study and other sources documented above are presented in table 1 to indicate the POPs residues found in a typical daily diet in the western United States. Information on dioxin contamination is included where data are available.

Results show that a typical daily diet in the western US could potentially deliver 66 "hits" of POPs exposure, while 
Table 2 Hazard rankings of selected persistent organic pollutants

\begin{tabular}{|c|c|c|c|c|c|c|c|}
\hline \multirow[b]{2}{*}{ Chemical(s) } & \multicolumn{2}{|c|}{$\begin{array}{l}\text { Acute hazard } \\
\text { rating* }\end{array}$} & \multicolumn{2}{|l|}{ Cancer rating $\dagger$} & \multirow{2}{*}{$\begin{array}{l}\text { Endocrine } \\
\text { disruptor } \\
\text { status } \ddagger\end{array}$} & \multicolumn{2}{|c|}{$\begin{array}{l}\text { US EPA RfD and ATSDR MRL } \\
(\mathrm{mg} / \mathrm{kg} / \mathrm{day}) \S\end{array}$} \\
\hline & WHO & US EPA & IARC & US EPA & & US EPA & ATSDR \\
\hline Aldrin & $\mathrm{lb}$ & 1 & & B2, Probable & Yes & $3 \times 10^{-5}$ & $3 \times 10^{-5}$ \\
\hline Chlordane & $\|$ & $\|$ & 2B, Possible & B2, Probable & Yes & $5 \times 10^{-4}$ & $6 \times 10^{-4}$ \\
\hline DDT, DDE & $\|$ & $\|$ & 2B, Possible & B2, Probable & Yes & $5 \times 10^{-4}$ & $5 \times 10^{-4}$ \\
\hline Dieldrin & NA & $\|$ & 3, Unclassifiable & B2, Probable & Yes & $5 \times 10^{-5}$ & $5 \times 10^{-5}$ \\
\hline 2,3,7,8-Tetrachloro-dibenzo-p-dioxin & NA & । & 1 , Known & A, Known & Yes & NA & $1 \times 10^{-9}$ \\
\hline $2,3,4,7,8$-Penta-chlorodibenzofuran $\rrbracket$ & NA & i & 1 , Known & A, Known & Yes & NA & $3 \times 10^{-8}$ \\
\hline Endrin & $\mathrm{lb}$ & i & 3, Unclassifiable & D, Unlikely & Yes & $3 \times 10^{-4}$ & $3 \times 10^{-4}$ \\
\hline Heptachlor & $\|$ & $\|$ & 2B, Possible & B2, Probable & Yes & $5 \times 10^{-4}$ & NA \\
\hline Hexachlorobenzene & la & IV & 2B, Possible & B2, Probable & Yes & $8 \times 10^{-4}$ & $2 \times 10^{-5}$ \\
\hline Mirex & NA & $\|$ & 2B, Possible & NA & Yes & $2 \times 10^{-4}$ & $8 \times 10^{-4}$ \\
\hline $\mathrm{PCBs}$ * * & NA & NA & 2A, Probable & B2, Probable & Yes & $\begin{array}{l}7 \times 10^{-5}(1060) \\
2 \times 10^{-5}(1254)\end{array}$ & $2 \times 10^{-5}(1254)$ \\
\hline Toxaphene & NA & $\|$ & 2B, Possible & B2, Probable & Yes & NA & $1 \times 10^{-3}$ \\
\hline
\end{tabular}

*Acute ratings from the World Health Organisation (WHO) are based on oral, dermal, or inhalation $\mathrm{LD}_{50}$ values: la, extremely hazardous; Ib, highly hazardous; II, moderately hazardous; III, slightly hazardous. Acute ratings from the US Environmental Protection Agency are based on US National Toxicology Program oral rat $L_{50}$ data: ${ }^{24} I, L_{50}<50 \mathrm{mg} / \mathrm{kg} ; \mathrm{II}, \mathrm{LD}_{50}=50-500 ; I I I, \mathrm{LD}_{50}=500-5000 ; I$, $\mathrm{LD}_{50}>5000$. †International Agency for Research on Cancer (IARC) rating system. ${ }^{25}$ US EPA ratings from their Integrated Risk Information System (IRIS) database. ${ }^{26} \neq^{\prime \prime} Y e s^{\prime \prime}$ means there is published evidence of endocrine disruption in animals or humans for this chemical. ${ }^{27}$ §Reference doses (RfDs) are from the US EPA IRIS database. ${ }^{26}$ Minimal risk levels (MRLs) (oral, chronic or intermediate) from the Agency for Toxic Substances Disease Registry (ATSDR). ${ }^{28}$ IMost toxic isomer of this group of compounds.

* *RFDs given for two PCB mixtures: Aroclor 1060 and Aroclor 1254. US EPA has not come to a consensus value for the RFD for Aroclor 1248 because the lowest dose tested caused an infant death in a species of monkey that was tested. RfD for Aroclor 1260 was not available. Agency for Toxic Substances Disease Registry Minimal Risk Level (MRL) is only available for Aroclor 1254.

hypothetical daily meal plans developed for three other US regions could deliver between 63 and 70 POPs exposures per day. A traditional holiday dinner could deliver 38 hits in a single meal. The number of potential exposures found were as follows (these potential exposure estimates represent a worst case scenario, where every food item in the daily diet contains residues. Actual frequency of detection of these POPs pesticides among samples taken in the FDA study were $22 \%$ or less);

- Midwest US: 63 exposures per day

- North east US: 64 exposures per day

- South east US: 70 exposures per day

- Western US: 66 exposures per day

- Holiday dinner: 38 exposures in a single meal

According to FDA's Total Diet Study, POPs residues usually occur at less than 100 parts per billion (see appendix $C$ in reference 4 for concentration data). Research indicates, however, that even these low levels of exposure are cause for concern (for an excellent overview of the recent research on low level exposure and its effects, see Schettler T, Stein J, Reich F, et al. In harm's way: toxic threats to child development. Boston: Greater Boston Physicians for Social Responsibility, 2000). ${ }^{14-17}$ Various US and international agencies have established maximum POPs exposure levels, above which they have determined there is significant cause for concern about increased risk of both cancer and non-cancer effects. US Agency for Toxic Substances and Disease Registry defines Minimal Risk Levels (MRLs) for hazardous substances, an estimate of the daily human exposure to a hazardous substance that is likely to be without appreciable risk of adverse non-cancer health effects over a specified duration of exposure (see http:// www.atsdr.cdc.gov/mrls.html). US EPA defines a Reference Dose (RfD) for noncancer toxicity of individual chemicals, a dose below which no ill effects are anticipated (see the US EPA Integrated Risk Information System (IRIS) database, http:// www.epa.gov/iris/). The World Health Organisation (WHO) defines an Acceptable Daily Intake (ADI) as the dose below which no ill effects are anticipated (see the WHO Chemical Contaminants in Food web site http://www.who.int/fsf/ Chemicalcontaminants/index2.htm). While there are some differences in the thresholds established by different health and environmental agencies, the levels of exposure triggering concern about potential health damage are generally extremely low ( see table 2 ). In the case of the pesticide dieldrin, both the ATSDR and EPA have set the level of concern for exposure at $0.05 \mu \mathrm{g} / \mathrm{kg}$ of body weight per day-a total of 3.5 $\mu \mathrm{g}$ of dieldrin per day for a $70 \mathrm{~kg}$ adult. This amount of dieldrin represents $0.000000005 \%$ of an average adult's body weight, similar to a drop of water in an Olympic size swimming pool (50 metres $\times 25$ metres $\times 2$ metres).

Our findings indicate that the US food supply is contaminated with levels of POPs chemicals that result in exposures at or above the health based standards. Figure 1 shows that for children, dietary intake of the pesticide dieldrin can be well above risk thresholds set by government agencies. When it comes to protecting children from POPs, "safe" levels of exposure are even lower. Children eat disproportionately more of certain foods on a pound for pound body weight basis than does an average weight adult male. In addition, young children's bodies are engaged in a multitude of hormone directed developmental processes that are uniquely susceptible to disruption from POPs chemicals. Proportionately larger exposures and unique susceptibilities combine to make developing children much more vulnerable to the adverse effects of POPs than adults. The US Food Quality Protection Act of 1996 recognises that children are not simply small adults. After recommendations of an influential US National Academy of Sciences study, ${ }^{18}$ the law requires EPA to take into consideration the factors that make children uniquely vulnerable to the risks posed by pesticides in the food supply by building an additional safety factor into the risk assessment.

Unfortunately, the story of dieldrin exposure told by figure $\mathrm{l}$ is not the entire picture. Health based thresholds are established for individual chemicals, while actual diets may include PCB residues in a fish fillet, dieldrin in a serving of zucchini, and dioxin in an ice cream cone. Because these organochlorine chemicals often have similar types of adverse health effects (see below), the sum of the adverse effects of exposures to combinations of chemicals will be greater than that for exposure to a single chemical.

The results of this analysis also highlight a serious flaw in the US regulatory framework that is supposed to be protecting public health. When the residue level of a toxic chemical in a food product tested by FDA is at or higher than a specified FDA 


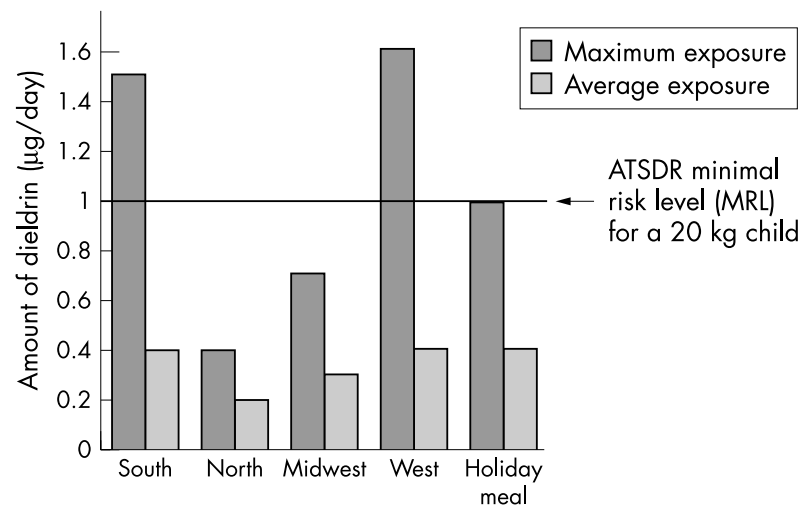

Figure 1 Comparison of dieldrin in regional daily diets and US health based risk thresholds.

"action level," FDA must remove the food from the market. However, evaluation of the action levels for POPs chemicals indicates that ingestion of foods contaminated at the FDA action level would result in exposures that significantly exceed the health based standards set by US EPA and ATSDR. As an example, consider a serving of fish contaminated with DDT residues equal to the amount permitted by FDA's action level. Because FDA's action level for DDT is significantly higher than health based standards set by EPA and ATSDR, consumption of this single serving of fish would expose a consumer to almost 50 times the daily exposure considered "safe" by those health based standards. If a glass of milk contained an amount of DDT equal to the level allowed by FDA's action level, it would contain nearly 10 times as much DDT as the daily exposure level considered safe by EPA and ATSDR.

As illustrated in table 3, eating a full day's diet of items contaminated with DDT at levels allowed by FDA would bring an adult's exposure to about 90 times the safe level established by ATSDR's health based standards (Minimal Risk Levels or "MRLs"). A child's exposure to amounts of DDT allowed by FDA action levels would be more than 300 times the health based standard. While the probability is low that an entire day's diet would consist of all items contaminated at FDA action levels, the data illustrate the dramatic extent to which FDA action levels fall short of other federal agency standards of public health protection.

\section{POPS ARE LINKED TO HEALTH PROBLEMS}

Some of the human health effects now linked to POPs exposure include cancer, learning disorders, impaired immune function, reproductive dysfunction (for example, low sperm counts, endometriosis-probably as a result of endocrine disruption), and diabetes. ${ }^{19-21}$

In the timeframe of widespread use of these persistent toxic chemicals, various disease registries and surveillance efforts show increased incidence of breast cancer, learning disabilities, infertility and reproductive system damage. No one can say with certainty the extent to which exposure to POPs is responsible for these trends; we are exposed to a variety of pesticides and other chemicals in our daily lives that certainly contribute to these diseases. Nevertheless, many studies indicate that exposure to POPs is linked to numerous chronic illnesses and developmental disorders.

Because many POPs chemicals exhibit similar modes of action on the human body, the health effects resulting from exposure to multiple chemicals can be substantially greater than those resulting from exposure to a single chemical. The effects are especially pronounced on a developing fetus or infant. ${ }^{22}$ The fact that additive and/or synergistic effects are common for POPs makes a strong case for banning the use of the entire class of chemicals, not just a few of the worst offenders.

\section{THE STOCKHOLM CONVENTION}

As long as POPs continue to be produced and used anywhere, they will continue to contaminate the food supply and threaten the health of people and ecosystems worldwide. The ubiquitous presence of these chemicals in the food supply and their extensive adverse effects both on human and environmental health creates a compelling and urgent need for action to prevent further release of these dangerous chemicals.

Recognising that the health risks from POPs can neither be managed by individual countries' regulators nor contained by national borders, the United Nations Environment Programme sponsored an international agreement, the Stockholm Convention, signed in May 2001, to phase out production, use, and release of POPs. ${ }^{23}$ Twelve POPs have been identified as initial phase out targets under the new treaty. As mentioned earlier, this list includes nine organochlorine pesticides and three industrial chemicals/byproducts. The Stockholm Convention is a promising vehicle for tackling POPs accumulation in the world's food supply.

\begin{tabular}{|c|c|c|c|}
\hline Food item & $\begin{array}{l}\text { Amount of food } \\
\text { ingested (g) }\end{array}$ & $\begin{array}{l}\text { FDA action level } \\
(\mu \mathrm{g} / \mathrm{g})^{*}\end{array}$ & $\begin{array}{l}\text { Total amount of } \\
\text { pesticide ingested }(\mu \mathrm{g})\end{array}$ \\
\hline Eggs & 125 & 0.50 & 62 \\
\hline Melon & 125 & 0.10 & 12 \\
\hline Milk & 250 & 1.25 & 312 \\
\hline Toast (grains) & 250 & 0.50 & 125 \\
\hline Carrots & 125 & 3.00 & 375 \\
\hline Cucumbers & 125 & 0.10 & 12 \\
\hline Tomatoes & 125 & 0.05 & 6 \\
\hline Spinach & 125 & 0.50 & 62 \\
\hline Radishes & 62 & 0.20 & 12 \\
\hline Fish & 372 & 5.00 & 1860 \\
\hline Eggplant & 125 & 0.10 & 12 \\
\hline Legume & 250 & 0.20 & 50 \\
\hline Potatoes & 250 & 1.00 & 250 \\
\hline Total & & & 3154 \\
\hline ATSDR MRL† (adult) & & & 35 \\
\hline ATSDR MRL $\ddagger$ (child) & & & 10 \\
\hline
\end{tabular}


The nine pesticides on this initial list have been banned or severely restricted in the United States since the 1970s and 1980s. Most industrialised countries and many developing countries also have banned or restricted the use of these pesticides. It is important to note that while other POPs pesticides, such as lindane and endosulfan, continue to be used in the US and are present in the US food supply, the focus of our study was limited to the initial list of chemicals targeted by the Stockholm Convention. Importantly, the Convention includes provisions for adding additional POPs chemicals in the future.

Given the widespread occurrence of POPs in the food supply and the serious health risks associated with even extremely small levels of exposure to POPs, prevention of further food contamination must be a national health policy priority in every country. Rapid implementation of the Stockholm Convention will prevent further accumulation of persistent toxic chemicals in food and give future generations the chance they deserve to experience life free from the dangers of persistent toxic chemicals. Fifty ratifications are needed to bring this important international agreement into effect; to date, five countries have ratified the Convention (as of April 2002, the following countries had ratified the Stockholm Convention: Canada, Fiji, Lesotho, Netherlands, and Samoa). Early ratification and rapid implementation of the treaty should be an urgent priority for all governments.

\section{ACKNOWLEDGEMENTS}

This work was made possible by grants from the Jenifer Altman Foundation, the Homeland Foundation, the Mitchell Kapor Foundation, and Joshua Mailman. Many individuals contributed to the original version of Nowhere to Hide. Thanks to coauthor Sharyle Patton, and to Charles Benbrook, Charlotte Brody, Monica Moore, Ted Schettler and Richard Wiles for feedback on the original version of this report.

\section{ADDENDUM}

As of 28 August 2002, 16 countries have ratified the treaty: Canada, Czech Republic, Fiji, Germany, Iceland, Lesotho, Liberia, Nauru, Netherlands, Norway, Rwanda, Samoa, Slovakia, Sweden, United Arab Emirates, Viet Nam.

\section{Authors' affiliations}

K S Schafer, S E Kegley, Pesticide Action Network North America, San Francisco, USA

Correspondence to: Kristin S Schafer, Pesticide Action Network North America, 49 Powell Street, Suite 500, San Francisco, CA 94102, USA; kristins@panna.org

Accepted for publication 23 April 2002

\section{REFERENCES}

1 Cummins JE. Extinction: the PCB threat to marine mammals. Ecologist 1988;60:18.

2 Solomon G, Weiss P. Environmental contaminants in breastmilk. San Francisco: Natural Resources Defense Council, September 2000. (http://www.nrdc.org/breastmilk)

3 Center for Health and Environmental Justice. A comprehensive list of studies of human contamination. Falls Church, VA: Center for Health and Environmental Justice, 2000
4 Schafer KS, Kegley SE, Patton S. Nowhere to hide: persistent toxic chemicals in the US food supply. San Francisco: Pesticide Action Network, 2001. (http://www.panna.org/resources/documents/ nowhereToHideAvail.dv.html)

5 Food and Drug Administration. Total diet study. Washington, DC: US Food and Drug Administration, September 2000. (http:// www.cfsan.fda.gov/ comm/tds-toc. html)

6 US Department of Agriculture. Pesticide data program. US Department of Agriculture. (http://www.ams.usda.gov:80/science/pdp/)

7 Groth E, Benbrook C, Lutz K. Do you know what you're eating? An analysis of US government data on pesticide residues in foods. Consumers Union of the US, February 1999. (http:// www.consumersunion.org/food/do_you_knowl.htm)

8 Groth E, Benbrook C, Lutz K. Update: pesticides in children's foods-an analysis of 1998 USDA PDP data on pesticide residues. Consumers Union of the US, February 2000. (http://www.consumersunion.org/ food/pdpdc600.htm)

9 US EPA Office of Research and Development. Estimating exposure to dioxin-like compounds. Volume II: properties, sources, occurrence and background exposures. Washington, DC: US EPA Office of Research and Development, June 1994: EPA/600/6-88/005Cb.

10 Schecter A Startin JC, Wright $M$, et al. Congener-specific levels of dioxins and dibenzofurans in US food and estimated daily dioxin toxic equivalent intake. Environ Health Persp 1994;102:962-6.

11 US Agency for Toxic Substances and Disease Registry. Minimal risk levels (MRLs) for hazardous substances. US Agency for Toxic Substances and Disease Registry, February 2000. (http://www.atsdr.cdc.gov/ mrls.html)

12 US Food and Drug Administration Center for Food Safety and Applied Nutrition. Pesticide program: residue monitoring 1998. Table 7. US Food and Drug Administration Center for Food Safety and Applied Nutrition, March 1999. (http://vm.cfsan.fda.gov/ dms/ pes98rep.html\#Table_7)

13 US Food and Drug Administration Center for Food Safety and Applied Nutrition. Pesticide program: residue monitoring 1999. Table 6. US Food and Drug Administration Center for Food Safety and Applied Nutrition, April 2000. (http://vm.cfsan.fda.gov/ dms/ pes99rep.html\#Table_6)

14 Solomon G, Schettler T. Generations at risk: reproductive health and the environment. Boston: MIT Press, 1999. (http://www.igc.org/psr/ ihw-report_dwnld.htm\#ihwRptDwnld)

15 Jacobson JL, Jacobson SW. Intellectual impairment in children exposed to polychlorinated biphenyls in utero. N Engl J Med 1996;335:783-9.

16 Guo YL, Hsu PC, Hsu CC, et al. Semen quality after prenatal exposure to polychlorinated biphenyls and dibenzofurans. Lancet 2000;356:1240-1.

17 Edmunds JSG, McCarthy RA, Ramsdell JS. Permanent and functional male-to-female sex reversal in d-rR strain medaka (Oryzias latipes) following egg microinjection of o, o'-DDT. Environ Health Persp 2000;108:219-24

18 National Research Council. Pesticides in the diets of infants and children. Washington, DC: National Academy Press, 1993.

19 Orris P, Chary LK, Perry K, et al. Persistent organic pollutants and human health. World Federation of Public Health Associations, USA, May 2000. (http://www.alpha.org/wfpha/popsfinal 1.pdf)

20 Colborn T, Dumanoski D, Myers JP. Our stolen future. New York: Penguin Books, 1996

21 Ribas-Fitó N, Sala M, Kogevinas $M$, et al. Polychlorinated biphenyls (PCBs) and neurological development in children: a systematic review. $J$ Epidemiol Community Health 2001;55:537-46.

22 Vonier PM, Crain DA, McLachlan JA, et al. Interaction of environmental chemicals with the estrogen and progesterone receptors from the oviduct of the american alligator. Environ Health Persp 1996:104:1318-22.

23 United Nations Environment Programme. Stockholm Convention. (http://www.chem.unep.ch/sc/)

24 US National Toxicology Program. Chemical health and safety data. (http://ntp-server.niehs.nih.gov/Main Pages/Chem-HS.html)

25 International Agency for Research on Cancer. Lists of IARC evaluations. (http://193.51.164.11/monoeval/grlist.html)

26 US Environmental Protection Agency. Integrated Risk Information System (IRIS). (http://www.epa.gov/iris)

27 Keith L. Environmental endocrine disruptors. New York: Wiley, 1997.

28 Agency for Toxic Substances Disease Registry. Minimal risk levels for hazardous substances. (http://www.atsdr.cdc.gov/mrls.html) 